\title{
LUC FRAISSE, Proust et la stratégie militaire
}

\section{Ludovico Monaci}

\section{OpenEdition \\ Journals}

\section{Edizione digitale}

URL: https://journals.openedition.org/studifrancesi/23007

DOI: 10.4000/studifrancesi.23007

ISSN: 2421-5856

\section{Editore}

Rosenberg \& Sellier

\section{Edizione cartacea}

Data di pubblicazione: 1 avril 2020

Paginazione: 209-210

ISSN: 0039-2944

\section{Notizia bibliografica digitale}

Ludovico Monaci, «Luc fraisse, Proust et la stratégie militaire», Studi Francesi [Online], 190 (LXIV | I) I 2020, online dal 01 mai 2020, consultato il 03 août 2021. URL: http://journals.openedition.org/ studifrancesi/23007 ; DOI: https://doi.org/10.4000/studifrancesi.23007

Questo documento è stato generato automaticamente il 3 août 2021.

\section{(c) (†)}

Studi Francesi è distribuita con Licenza Creative Commons Attribuzione - Non commerciale - Non opere derivate 4.0 Internazionale. 


\title{
LUC FRAISSE, Proust et la stratégie militaire
}

\author{
Ludovico Monaci
}

\section{NOTIZIA}

LUC FRAISSE, Proust et la stratégie militaire, Paris, Hermann, 2018, «Savoir lettres», 482 pp.

1 La Grande Guerra riveste un ruolo decisivo nel mutamento dei progetti editoriali di Marcel Proust: i critici sono unanimi nel sostenere che il primo conflitto mondiale riscrive le vicende narrate, i comportamenti e le sorti dei personaggi della Recherche. Fondandosi su queste evidenze assodate, instaurando un dialogo produttivo tra le pubblicazioni dei principali quotidiani dell'epoca e la corrispondenza autoriale, Luc Fraisse allarga tale prospettiva e mette in luce l'influenza esercitata dalle cronache militari sul testo di Proust.

2 Se l'«Introduction» (pp. 5-38) verte sulla necessità di approfondire in maniera organica i rapporti intrattenuti dall'autore con la "filosofia" bellica dell'epoca, la prima sezione («L'irruption de la guerre dans le roman», pp. 39-64) fornisce le chiavi di lettura e chiarisce l'atteggiamento di «engagement dans la neutralité» (p. 61) che Proust e il narratore adottano al cospetto delle vicissitudini militari.

3 Nella parte centrale della trattazione, Fraisse sottolinea quanto lo scrittore francese fosse un lettore scrupoloso degli avvenimenti del suo tempo. I brani della Recherche dedicati al discorso militare sono messi in relazione con le cronache più importanti che l'autore ebbe a leggere direttamente, ovvero Les Commentaires de Polybe di Reinach (pubblicati sul "Figaro"), La Situation militaire di Henry Bidou (pubblicata sul "Journal des débats") e Les opérations de guerre di Fernand Feyler (pubblicate sul "Journal de Genève"). La sezione "Joseph Reinach et le roman de la guerre» (pp. 65-130) pone in primo piano l'approccio sociologico (derivato dalla teoria dell'imitazione di Tarde) che la Recherche condivide con le cronache del politico francese Reinach. L'attenzione alla geografia dei campi di battaglia e la descrizione delle tattiche sono invece i cardini delle 
cronache di Bidou e trovano corrispondenze ben precise nelle modulazioni discorsive di Saint-Loup a Doncières («Henry Bidou et le secret des structures», pp. 131-230). «Le colonel Feyler et la science du déchiffrement» (pp. 231-376) arricchisce il panorama dal punto di vista di chi, pur sentendosi moralmente coinvolto nelle vicende belliche, guarda a queste con occhio neutrale. Marcata da forti tinte psicologiche e costantemente bilanciata tra politica e strategia, l'argomentazione di Feyler avanza alternativamente per induzioni e deduzioni: Proust sembra far adottare questo metodo dialettico a Saint-Loup, che rivede, riformula e rettifica nel Temps retrouvé le tesi avanzate in Le côté de Guermantes.

4 In continuità con le precedenti, la sezione «Auprès des généraux: comment saisir la pensée des chefs?» (pp. 377-428) coglie lo spunto da una lettera del 1919 (in cui lo scrittore dichiara di avere «le culte de Mangin, de Foch, de Joffre») per mostrare come, al di là degli universali quali le strategie militari, Proust si interessasse anche al pensiero dei singoli generali. L'«Épilogue» (pp. 429-438) traccia il bilancio finale: come lo stratega militare organizza i piani e le tattiche della battaglia, così Proust dissimula le proprie strategie e costruisce il proprio piano di azione romanzesca.

5 Nel complesso, il testo offre nuove possibilità di approccio alla Recherche: le argomentazioni, avanzate con spirito analitico da Luc Fraisse, convergono tutte sul fatto che il testo di Proust eredita dai discorsi militari dell'epoca non soltanto certe peculiarità linguistiche e certe prerogative sociologiche, ma anche e soprattutto delle istanze concettuali ed epistemologiche che condizionano sistematicamente l'impianto e la costruzione di un'opera letteraria la quale, per pervenire alla verità, deve ripercorrere e ridiscutere a ritroso gli assunti che parevano regolati da leggi imperscrutabili. 